\title{
Numerical Study of The Effect of Traffic Restriction on Air Quality in Beijing
}

\author{
Qizhong $\mathrm{Wu}^{1,2,3}$, Zifa Wang ${ }^{1}$, A. Gbaguidi ${ }^{1}$, Xiao Tang ${ }^{1,2}$ and Wen Zhou ${ }^{3}$ \\ ${ }^{1}$ LAPC/NZC, Institute of Atmospheric Physics, Chinese Academy of Sciences, Beijing, China \\ ${ }^{2}$ Graduate University of Chinese Academy of Sciences, Beijing, China \\ ${ }^{3}$ Guy Carpenter Asia-Pacific Climate Impact Centre, School of Energy and Environment, \\ City University of Hong Kong, Hong Kong, China
}

\begin{abstract}
The Nested Air Quality Prediction Modeling System (NAQPMS), in coupling with the fifth-generation NCAR/Penn State Mesoscale Model (MM5), is employed to assess the impact of vehicle traffic restriction on air quality in Beijing within preOlympic environmental measures implemented from $17^{\text {th }}$ to $20^{\text {th }}$ August 2007. Predictions are compared against meteorological and air quality observed data and validation shows model good performance as a whole. Sensitivity experiments, including the baseline and traffic control scenarios, are designed to estimate the potential reduction of nitrogen dioxide $\left(\mathrm{NO}_{2}\right)$ and particulate matter (PM10) concentrations during the traffic restriction. Results indicate that the $\mathrm{NO}_{2}$ concentration in Urban Beijing is reduced by $16 \% \sim 32 \%$, with the average of $21 \%$, while $\mathrm{NO}_{x}$ emissions are lowered within $28 \%$; the primary PM10 concentrations is also reduced by $6 \% \sim 15 \%$, lower than the decreased percentages of $\mathrm{NO}_{2}$ concentration. The results show that the most significant reduction of air pollutants occurs in Urban Beijing where the restriction has been mainly imposed. This study demonstrates the efficiency of traffic restriction measure in air quality improvement over Beijing.
\end{abstract}

\section{Introduction}

Challenge and opportunity characterized the award of the 2008 Olympic Games to Beijing. China's rapid economic development, with GDP growing at more than $10 \%$ per year, has generated widespread concern about the environmental implications for the world.

As known, vehicles in Beijing produced more than 100,000 tons of $\mathrm{NO}_{x}$ per year (Hao et al. 2001), contributed to $46 \%, 78 \%$ and $83 \%$ of $\mathrm{NO}_{x}, \mathrm{CO}$ and $\mathrm{HC}$ emissions, respectively (Hao et al. 2006). Also, vehicle tailpipe emissions and road fugitive dust contributed to $13.6 \%$ and $32.8 \%$ of PM10 ambient concentration respectively (Chan et al. 2005; Hao et al. 2006). Within gas phase species, $\mathrm{NO}_{2}$ is the major contributor but particles are the most important pollutants for visibility. Health effects may include increased susceptibility to respiratory illness and reduced lung capacity (Street et al. 2007).

In that context, one of implemented actions consisted of traffic restriction plan through alternative odd-even plates numbered calendar by Beijing-registered automobiles applied from $17^{\text {th }}$ to $20^{\text {th }}$ August 2007 to test the impact of traffic on Beijing air quality. It was the first experimented vehicles traffic restriction in Beijing. Due to the fact that traffic restrictions implemented during Beijing Olympics 2008 were combined with many other emissions abatement measures, making difficult separating modeling evaluation of traffic restriction effect, the environment test during the 17 20 $0^{\text {th }}$ August 2007 offers suitable conditions to properly quantify the potential impact of vehicular emissions abatement on air quality in Beijing.

In this paper, the model is used to illustrate the effect of the

Corresponding author and present affiliation: Zifa Wang, Institute of Atmospheric Physics, Chinese Academy of Sciences, Beijing, 100029, China. E-mail: zifawang@mail.iap.ac.cn. (C2010, the Meteorological Society of Japan. traffic restriction on air quality in Beijing, particularly $\mathrm{NO}_{2}$ and PM10 variations. Previously, analysis on $\mathrm{NO}_{\mathrm{x}}$ reduction within traffic restriction during Sino-African Summit was performed using the Dutch-Finnish Ozone Monitoring Instrument (OMI) satellite data (Wang et al. 2007). Similarly, based on two emissions scenarios (baselines and control scenario) under the same meteorological field, the main purpose of the present modeling study is therefore to quantify the contribution of the traffic restriction implemented during the Pre-Olympic period, to air quality improvement over Beijing. The effect of the traffic restriction is not only examined in Urban Beijing, but also in surrounding suburban areas.

\section{Methodology}

\subsection{Model description and setup}

The chemical transport model used in this work is the NAQPMS, developed by the Institute of Atmospheric Physics, Chinese Academy of Sciences. The model consists of a threedimensional system with various options for representing the physical and chemical processes describing regional and urban scale atmospheric pollution (Wang et al. 2006). Its chemical transport module reproduces the physical and chemical evolution of reactive pollutants by solving the mass balance equation following vertical coordinates (Wang et al. 2001). The gas chemistry mechanism has been updated to CBM-Z (Li et al. 2007).

\subsection{Meteorological simulation}

The MM5 v3.6 is used as meteorological driver for the NAQPMS. National Centers for Environmental Prediction (NCEP) final analysis data $(\mathrm{FNL})$, with $1^{\circ} \times 1^{\circ}$ spatial resolution and four times a day temporal resolution, is used as the initial and boundary condition for the MM5 simulations. The selected schemes for the present study are simple ice for explicit moisture, Grell cumulus, $\mathrm{MRF}$ for PBL and cloud scheme for atmospheric radiation (Gao et al. 2007).

Four nested grids for horizontal resolution of $81 \mathrm{~km}, 27 \mathrm{~km}$, $9 \mathrm{~km}$ and $3 \mathrm{~km}$ with the center located at $\left(35.0^{\circ} \mathrm{N}, 110^{\circ} \mathrm{E}\right)$ were used for both MM5 and NAQPMS models shown in Fig. 1. The NAQPMS model has 20 vertical layers extending from $1000 \mathrm{hPa}$ to $100 \mathrm{hPa}$ with the p-level vertical coordinate, and is interpolated from 23 sigma levels of MM5 using INTERPB module. The simulation period is $10^{\text {th }} \sim 21^{\text {st }}$ August 2007 , with predicting cycle method, consisting of making 36-hr simulation and taking the last 24-hr simulation as NAQPMS meteorological driver in every predicting cycle, since the MM5 simulations are initialized with a cold start, and might take at least 12 hours on average for the model to spin up (Colle et al. 1999; JEFF C. F. Lo et al. 2007).

The MM5 simulation with gridded FDDA (four dimensional data assimilation) using Newtonian nudging is accounted to restrain the model's solutions from deviation. The land use data in Beijing (shown in Fig. 1), provided by the Beijing Institute of Surveying and Mapping (BISM), is updated to improve MM5 simulation.

Evaluation of MM5's meteorological hourly simulated results at the surface layer of domain 4 is performed by statistical parameters, including Mean bias (MB), Normal mean bias (NMB), Normal mean error (NME) and Correlation coefficient (R), at six meteorological stations in Urban Beijing. The statistical results in 

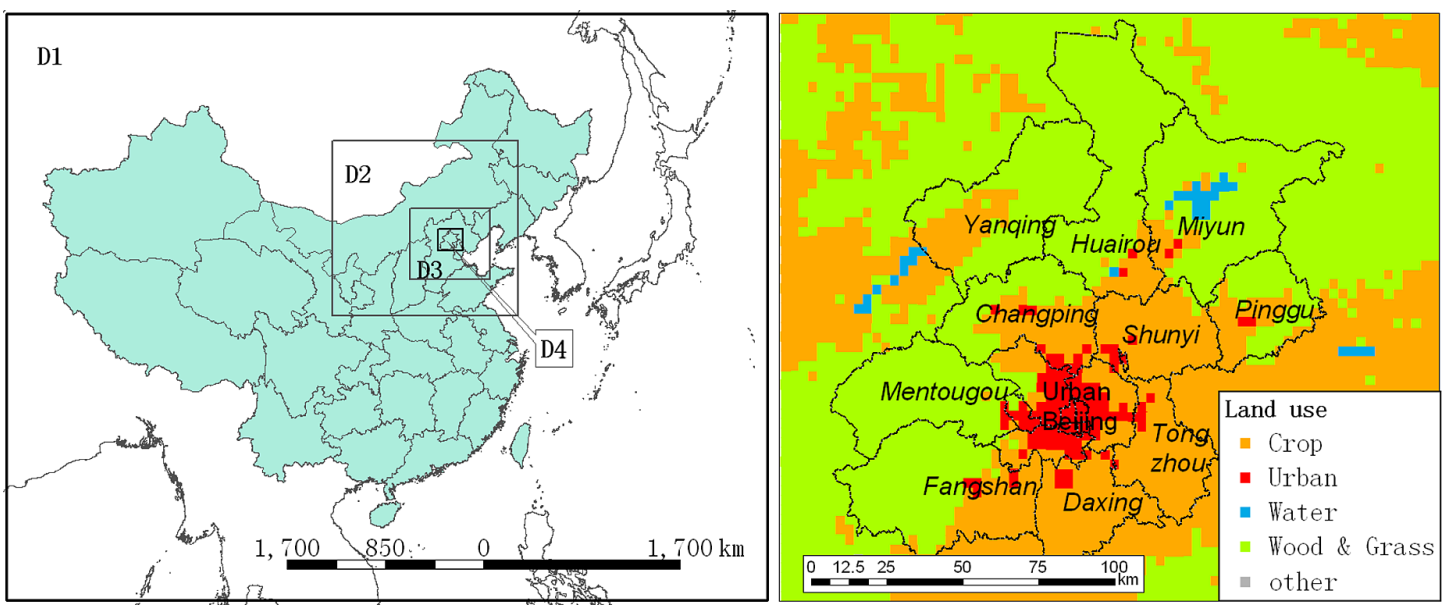

Fig. 1. The four nested domains used for simulation. Left: D1 covers East Asia with $83 \times 65$ grids; D2 with $61 \times 58$ grids includes North China; D3 with 79 $\times 70$ grids consists of Beijing and its surrounding. D4 with $73 \times 64$ grids covers Beijing. Right: Updated land use data in D4 with its county name.

Table 1. Statistical parameter of the MM5 performance. The unit of NMB and NME is $\%$.

\begin{tabular}{lrrrrrc}
\hline \multicolumn{1}{c}{ Var } & Obs. & Sim. & MB & NMB & NME & R \\
\hline $\mathrm{T}\left({ }^{\circ}\right)$ & 27.2 & 29.3 & 2.1 & 8.5 & 9.0 & 0.84 \\
$\mathrm{Rh}(\%)$ & 68.6 & 52.8 & -15.8 & -20.6 & 22.9 & 0.65 \\
$\mathrm{Ws}\left(\mathrm{m} \mathrm{s}^{-1}\right)$ & 1.36 & 2.08 & 0.72 & 111.1 & 138.6 & 0.26 \\
$\mathrm{P}(\mathrm{hPa})$ & 1001.0 & 999.5 & -1.5 & -0.15 & 0.18 & 0.96 \\
\hline
\end{tabular}

Table 1 show in general that MM5 is able to simulate the characteristics of temperature $(\mathrm{T})$, relative humidity $(\mathrm{Rh})$ and pressure (P). However, the model over-predicts the wind speed (Ws) with the NMB and NME higher than 50\%.

Note that the locations of the six concerned stations (Olympic center, Wukesong, Xiannongtan, Guangxiangtai, Chaoyang and Shunyi Station) are shown in Supplement 1.

\subsection{Emission process and scenario setting}

The Sparse Matrix Operator Kernel Emissions (Houyoux and Vukovich 1999) model is applied to deal with the emissions inventory and provide gridded emission data for the NAQPMS model. Three categories of emissions are considered in this study: the regional emission inventory from TRACE_P (Streets et al. 2003) with $10 \mathrm{~km}$ resolution, updated for the year 2002; the power plant emission database of Beijing and its surrounding provinces including Tianjin, Hebei, Shanxi, Inner Mongolia and Shandong provinces; detailed local source emissions database of Beijing city from the Beijing Environmental Protection Bureau (EPB), with base-year of 2004.

In order to obtain high resolution of emissions, the area emissions of Beijing have been spatially allocated based on related spatial factor, such as its population data provided from Land Scan 2005 Global Population Database. The road dust emission is spatially distributed according to the road length density; the compiled road statistics include arterial and local ways. Point source emissions (power plant and other large point sources) are also updated according to the study of (Hao et al. 2007), and accounted into the SMOKE model.

Based on the Road Network in Beijing, the traffic flow from Beijing Transport Research Center (BTRC, report 2007) and the mobile emissions provided from the Tsinghua University, we estimated the spatial distribution of the mobile emissions using the SMOKE mobile module. The traffic flow data has been also collected from (BTRC, report 2007), and evaluated on each class road of each county. With the road-length (RLength) and the traffic flow (TFlow) on each class road in counties, the Vehicle Miles Traveled (VMT) is calculated as following:

$$
\begin{aligned}
& V M T_{\text {(county, rclass) }}=R \operatorname{Rength} h_{\text {(county, rclass) }} \times \operatorname{TFlow} w_{\text {(county, rclass) }}, \\
& V M T_{\text {(county, rclass, vtype) }}=V M T_{\text {(county, rclass) }} \times \operatorname{Rate}_{(\text {vtype) }},
\end{aligned}
$$

where the "vtype" is vehicl type, the "rclass" is road class and the "Rate $($ vtype) " is the rate of the "vtype" vehicles in each county. The units of RLength, TFlow, VMT and Rate (vtype) are mile, number per year, mile per year and \%. With the same fuel content in each county, the VMT and the averaged speed of vehicles of each county, road class and vehicle type are input into SMOKE mobile module, while the meteorological factor is provided from the MM5 model to estimate the model-ready gridded mobile emissions. Taking into account the spatial distribution of the SMOKE mobile emission as horizontal factor, and combining with the amount of the mobile emissions from the Tsinghua University, we estimate the mobile emission in Beijing.

\section{a. Baseline scenario}

The total amount of emissions in Beijing for baselines scenario (without traffic restriction) is provided and compared with the emissions inventory in Beijing reported by Streets et al. (2003) (Table 2). Comparison shows that although the number of the vehicles increased rapidly in recent years, the $\mathrm{NO}_{\mathrm{x}}, \mathrm{CO}$ and volatile organic compound (VOC) emissions did not display obvious increment, indicating the effectiveness of the restricted standards for vehicles.

\section{b. Control scenario}

The daily traffic restriction covered inner-Ring6 from 6 am to $11 \mathrm{pm}$. In the control scenario of this study, the mobile emission was reduced from 6 am to 11 pm (Beijing Time) during $17 \sim 20^{\text {th }}$ August, 2007 according to estimated decreased emissions in Beijing, provided by the Department of Environment Sciences and Engineering, Tsinghua University (Table 3). The difference of $\mathrm{NO}_{\mathrm{x}}$ and primary PM10 emissions between baselines and control scenario are displayed in Fig. 2; the delta-emit corresponding to subsequent pollutants reduction is defined as baselines scenario

Table 2. The amount of emissions in Beijing in some studies. (Unit: $10^{3}$ tons $\mathrm{yr}^{-1}$ )

\begin{tabular}{lcccc}
\hline \multicolumn{1}{c}{ Species } & $\mathrm{NO}_{\mathrm{x}}$ & $\mathrm{PM} 10$ & $\mathrm{CO}$ & $\mathrm{VOC}$ \\
\hline This study & 201.3 & 157.3 & 1275.8 & 345.2 \\
(Streets et al. 2003) & 228.1 & - & 2727.6 & 394.9 \\
(Streets et al. 2007) & 212.4 & 66.0 & 2340.0 & 339.6 \\
(Ohara et al. 2007) & 232.5 & - & 1690.0 & - \\
(An X et al. 2007) & 227.3 & 106.9 & 1021.8 & 285.6 \\
\hline
\end{tabular}




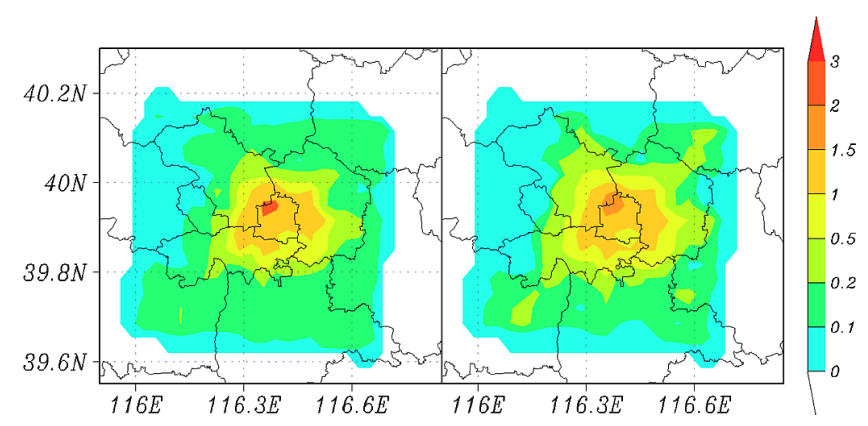

Fig. 2. The spatial distribution of decreased $\mathrm{NO}_{\mathrm{x}}\left(\mu \mathrm{g} \mathrm{m} \mathrm{m}^{-3} \mathrm{~s}^{-1}\right.$, left $)$ and PM10 ( $\mu \mathrm{g} \mathrm{m}^{-3} \mathrm{~s}^{-1}$, right) emissions between the baseline scenario and traffic restriction control scenario.

Table 3. The amount of decreased emissions in Beijing according to the traffic restriction.

\begin{tabular}{lrrrr}
\hline \multicolumn{1}{c}{ Species } & \multicolumn{1}{c}{$\mathrm{NO}_{\mathrm{x}}$} & $\mathrm{PM} 10$ & $\mathrm{CO}$ & \multicolumn{1}{c}{$\mathrm{VOC}$} \\
\hline$\Delta$ Emission (tons/3dys) & 350 & 114.1 & 4244 & 414 \\
$\Delta$ Emission (tons/yr) & 42583 & 13881 & 516350 & 50370 \\
\hline
\end{tabular}

emission values minus control scenario emission values during the traffic restriction. Note that, baseline emissions are unchaged outer Ring-6.

\section{Results and discussion}

\subsection{Meteorological synoptic analysis}

The weather condition was stable over Beijing region during the traffic restriction. There was an adverse weather conditions characterized by diurnal high temperature $\left(32^{\circ}\right)$, weak wind speed $\left(<1 \mathrm{~m} \mathrm{~s}^{-1}\right)$ with high pressure, weak variation of relative humidity, generally unfavorable for pollutants transport and diffusion, and may catalyze high pollution. Actually, such weather is favorable for assessing pollutants concentration variations between baselines scenario and control scenario since the weak pollutants transport minimizes uncertainties.

\subsection{Nitrogen dioxide $\left(\mathrm{NO}_{2}\right)$ concentration variation}

For predictions evaluation, daily monitoring concentrations of PM10 and $\mathrm{NO}_{2}$ over the National Standard Air Quality Observation Stations (NSAQ Stations), provided by EPB, are compared against NAQPMS results. NSAQ Stations located at the urban are shown in Supplement 1.

Under both scenarios, simulated and observed $\mathrm{NO}_{2}$ concentrations in Urban Beijing show good agreement (Fig. 3). This illustrates the accuracy of emission used in this study as discussed in Section 2.3.

The averaged reduction ratio of $\mathrm{NO}_{2}$ concentration from $17^{\text {th }}$ to $20^{\text {th }}$ August is estimated as about $21 \%$ in Urban Beijing. Decreased $\mathrm{NO}_{\mathrm{x}}$ emission in traffic control scenario is more than 42,000 tons/yr, versus more than 200,000 tons/yr in the whole Beijing City and 113,000 tons/yr in Urban Beijing in the baseline scenario. The daily reduction ratio of $\mathrm{NO}_{\mathrm{x}}$ emission is $37 \%$ in Urban Beijing from 6 am to $11 \mathrm{pm}$ during the traffic restriction; the average reduction ratio of $\mathrm{NO}_{\mathrm{x}}$ emission from August $17^{\text {th }}$ to August $20^{\text {th }}$ is about $28 \%$, greater than that of $\mathrm{NO}_{2}$ concentration. Since the present study is focused mainly on the relative changes in emissions during the traffic restriction, under the same meteorological conditions, the systematic errors associated with the model simulation and systematic mismatches in emission sources, are not expected to influence significantly conclusions drawn from the present analysis. Thus, one of the plausible reason of the discrepancy between $\mathrm{NO}_{2}$ and $\mathrm{NO}_{\mathrm{x}}$ reduction percentages is the influence of atmospheric complex diurnal and nighttime's interac-
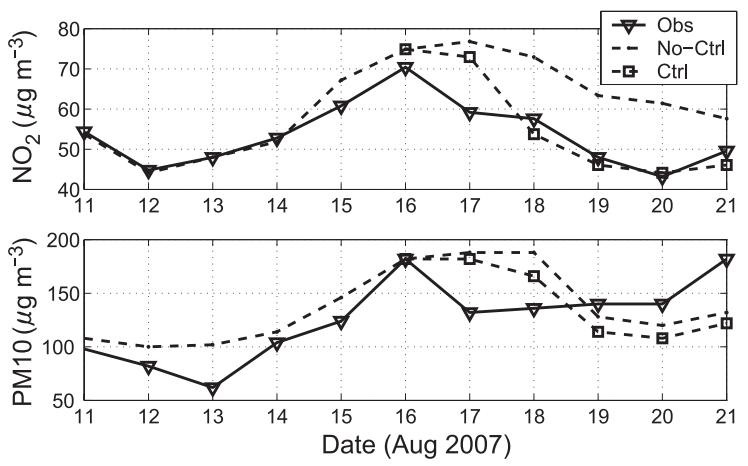

Fig. 3. The time series of $\mathrm{NO}_{2}$ and PM10 averaged from the eight NSAQ Stations (locations of these stations are shown in Supplement 1) in Urban Beijing from $11^{\text {th }}$ to $21^{\text {st }}$ August. The solid line is observation, published by Beijing EPB; the dashed line is the NAQPMS simulation under Baseline scenario without traffic restriction; the dashed line with square mark is the NAQPMS simulation under control scenario with traffic restriction.

tions among $\mathrm{NO}, \mathrm{NO}_{2}$ and other chemical compounds such as $\mathrm{OH}$, $\mathrm{HNO}_{3}, \mathrm{NO}_{3}, \mathrm{~N}_{2} \mathrm{O}_{5}$ etc. which govern photochemical pollution as well as $\mathrm{NO}_{2}$ decay and lifetime (Uno et al. 2007; Gbaguidi et al. 2007). This means that $\mathrm{NO}_{2}$ concentration variations depend not only on variations in $\mathrm{NO}_{\mathrm{x}}$ emissions but also on other chemical mechanisms leading to $\mathrm{NO}_{2}$ and $\mathrm{NO}_{\mathrm{x}}$ different sensitivities to the traffic restriction.

Figure 4 shows the spatial distribution of the reduction ratio of $\mathrm{NO}_{2}$ concentrations in the urban area and its northern counties. The $\mathrm{NO}_{2}$ concentration in the urban area has been reduced by $16 \% \sim 32 \%$, since the traffic restriction has been mainly in Urban Beijing within the Ring-6, where vehicles traffic network is the densest. The $\mathrm{NO}_{2}$ concentrations in most Huairou county and partly of Changping and Shunyi counties, which located at the north of Beijing, were reduced by more than $6 \%$. The effect of $\mathrm{NO}_{2}$ concentration reduction due to the traffic restriction was spread to above northern counties by the south wind during this period.

\subsection{PM10 concentrations variation}

Similar as $\mathrm{NO}_{2}$, predicted PM10 concentrations under both scenarios are compared against observed data in Urban Beijing (Fig. 3). Details of temporal variations in the spatial variations of PM10 mass concentrations in vicinity of the urban center areas from $15 \sim 20^{\text {th }}$ August are shown in Supplement 2. Except the prediction on 13 August, modeled PM10 concentrations in Urban Beijing agree well with the observation before traffic restriction period (11 16 ${ }^{\text {th }}$ August), while large discrepancy appears between simulated and observed PM10 concentration during the traffic restriction, especially on the first day ( $17^{\text {th }}$ August). This shows that the model prediction for PM10 $(\mathrm{NME}=13 \%)$ is worse than that of $\mathrm{NO}_{2}(\mathrm{NME}=3 \%)$ within $11^{\text {th }} \sim 15^{\text {th }}$ August. In addiction, observed trends show larger decrease of PM10 concentration than that of modeled; such discrepancy might be due to other mechanisms involving uncertainties in PM10 simulation.

The PM10 reductions occur mainly in Urban Beijing and its surrounding northern county, similarly to the spatial extent of $\mathrm{NO}_{2}$ reduction region focused above according to the dominant wind direction. In the urban, the reduced concentration of primary PM10 is about $1 \mu \mathrm{g} \mathrm{m}^{-3} \sim 5 \mu \mathrm{g} \mathrm{m}^{-3}$, with $6 \% \sim 15 \%$ as resulting ratio; reduced PM10 emission is estimated as about $10 \%$. The traffic restriction reduces both the primary PM10 from vehicles and the secondary PM10 from photochemical reactions. The latter is usually in fine mode (PM2.5) as inhalable particles.

All the data used for the validation analysis (Fig. 3) were obtained within the Urban Beijing area where impacts of reduction in emissions are expected to be greatest. Evaluations of the impact of the emission reduction are carried out over further downwind area (suburban area) in this study (Fig. 4), although validations of model predictions are not made there. For the case of PM10, 


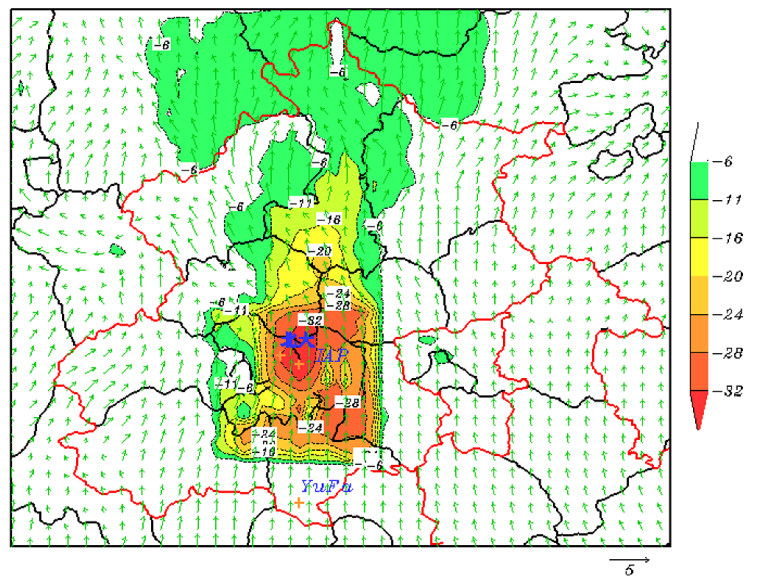

Fig. 4. The spatial distribution of $\mathrm{NO}_{2}$ concentration reduced ratio (\%), averaged from August 17 ${ }^{\text {th }}, 00: 00$ to August $20^{\text {th }}, 23: 59$. The unit of arrow is $\mathrm{m} \mathrm{s}^{-1}$.

observed values in the suburban area are shown in Supplement 2.

\section{Conclusion and discussions}

Vehicles traffic restrictions implemented during pre-Olympics period efficiently reduced $\mathrm{NO}_{x}$ emissions by $28 \%$, and $\mathrm{NO}_{2}$ concentration by $21 \%$ in Urban Beijing. Primary PM10 also have been reduced in the ranges of $6 \% \sim 15 \%$. Such sectoral restriction measure periodically implemented would contribute to improve air quality in Beijing. The effect of traffic restriction is more pronounced on $\mathrm{NO}_{2}$ concentration than that on PM10 in Urban Beijing.

However, regarding the relative lower percentages obtained for pollutants reduction, we conclude that only private vehicles traffic restriction may not be sufficient to achieve a veritable reduction of vehicular emissions in Beijing. A campaign of restriction extended to other categories of vehicles should be further analyzed and implemented.

In addition, considering uncertainties in emissions, proper detailed data on vehicles energy usage will be necessary to develop a more precise vehicular emissions. The air quality in Beijing notably in summertime might be determined by the meteorology which may increase no man-made emissions; thus any further air pollution control strategy in Beijing should be implemented in considering relationships among anthropogenic, and no man-made pollutants sources and meteorology. This is necessary for proper investigation on air quality in Beijing and regional implications.

\section{Acknowledgment}

This work is funded by the National Basic Research 973 Grant (2005CB422205) and NSFC grant (40775077).

\section{Supplements}

The Locations Monitoring Station and details variations of PM10 mass concentration in the urban are included in Supplement 1 and Supplement 2.

\section{References}

An, X., T. Zhu, Z. Wang, C. Li, and Y. Wang, 2007: A modeling analysis of a heavy air pollution episode occurred in Beijing. Atmos.
Chem. Phys., 7, 3103-3114.

BTRC, 2007: Beijing Transport Annual Report 2006, Beijing Transport Research Center, Beijing, China.

Chan, C. Y., X. D. Xu, Y. S. Li, K. H. Wong, G. A. Ding, L. Y. Chan, and X. H. Cheng, 2005: Characteristics of vertical profiles and sources of PM2.5, PM10 and carbonaceous species in Beijing. Atmos. Environ., 39, 5113-5124.

Colle, B. A., K. J. Westrick, and C. F. Mass, 1999: Evaluation of MM5 and Eta-10 Precipitation Forecasts over the Pacific Northwest during the Cool Season. Wea. Forecasting, 14, 137-156.

Gao, Y. Y., J. He, and Z. Wang, 2007: Simulation for impact of urbanization on meteorological conditions in Beijing area. Journal of Meteorology and Environment, 23, 58-64, (in Chinese).

Gbaguidi, A. E., J. Chen, Z. Wang, and C. Gao, 2007: Seasonal interactive relationships between tropospheric nitrogen dioxide surface concentration and nitrate dry deposition over China winter/summer compared analysis. Progress in Environmental Sciences and Technology, 1, 32, USA.

Hao, J., Y. Wu, L. Fu, K. B. He, and D. Q. He, 2001: Motor Vehicle Source Contributions to Air Pollutants in Beijing. Environmental Science, 22, 1-6, (in Chinese).

Hao, J., J. Hu, and L. Fu, 2006: Control vehicular emissions in Beijing during the last decade. Transportation Research Part A: Policy and Practice, 40, 639-651.

Hao, J., L. Wang, M. Shen, L. Li, and J. Hu, 2007: Air quality impact of power plant emissions in Beijing. Environmental Pollution, 147, 401-408.

Houyoux, M. R., and J. M. Vukovich, 1999: Updates to the Sparse Matrix Operator Kernel Emissions (SMOKE) Modeling System and Integration with Models-3. Environmental Programs MCNC, North Carolina Supercomputing Center, 3021 Cornwallis Road, Research Triangle Park, NC, 27709-2889.

Li, J., Z. Wang, H. Akimoto, C. Gao, P. Pochanart, and X. Wang, 2007: Modeling study of ozone seasonal cycle in lower troposphere over east Asia. J. Geophys. Res., 112, doi:10.1029/2006 JD008209.

Lo, J. C. F., A. K. H. Lau, F. Chen, J. C. H. Fung, and K. K. M. Leung, 2007: Urban Modification in a Mesoscale Model and Effect on the Local Circulation in the Pearl River Delta Region. J. Appl. Meteor. Climatol., 46, 457-476.

Ohara, T., H. Akimoto, J. Kurokawa, N. Horii, K. Yamaji, X. Yan, and T. Hayasaka, 2007: An Asian emission inventory of anthropogenic emission sources for the period 1980-2020. Atmos. Chem. Phys., 7, 4419-4444.

Streets, D. G., T. C. Bond, G. R. Carmichael, S. D. Fernandes, Q. Fu, D. He, Z. Klimont, S. M. Nelson, N. Y. Tsai, M. Q. Wang, J.-H. Woo, and K. F. Yarberi, 2003: An inventory of gaseous and primary aerosol emission in Asia in the year 2000. J. Geophys. Res., 108, doi:10.1029/2002JD003093.

Streets, D. G., J. S. Fu, C. J. Jang, J. Hao, K. He, X. Tang, Y. Zhang, Z. Wang, Z. Li, Q. Zhang, L. Wang, B. Wang, and C. Yu, 2007: Air quality during the 2008 Beijing Olympic Games. Atmos. Environ., 41, 480-492.

Uno, I., Y. J. He, T. Ohara, K. Yamaji, J. Kurokawa, M. Katayama, Z. Wang, K. Noguchi, S. Hayashida, A. Richter, and J. P. Burrows, 2007: Systematic Analysis of Interannual and Seasonal Variations of Model-simulated Tropospheric $\mathrm{NO}_{2}$ in Asia and comparison with GOME-satellite data. Atmos. Chem. Phys. Discuss., 6. 11181-11207.

Wang, Y., M. B. McElroy, K. F. Boersma, H. J. Eskes, and J. P. Veefkind, 2007: Traffic restrictions associated with the Sino-African summit: Reductions of $\mathrm{NO}_{\mathrm{x}}$ detected from space. Geophys. Res. Lett., 34, L08814, doi:10.1029/2007GL029326.

Wang, Z., T. Maeda, M. Hayashi, L.-F. Hsiao, and K.-Y. Liu, 2001: A nested air quality prediction modeling system for urban and regional scales, application for high-ozone episode in Taiwan. Water Air Soil Pollut., 130, 391-396.

Wang, Z., X. Fu, X. Wang, J. An, and J. Zhu, 2006: Development and Application of Nested Air Quality Prediction Modeling System. Chinese Journal of Atmospheric Sciences, 30, 778-790, (in Chinese).

Manuscript received 8 January 2010, accepted 7 May 2010

SOLA: http://www.jstage.jst.go.jp/browse/sola/ 